\title{
A concerted SCF-MO ab initio and vibrational spectroscopic study of the conformational isomerism in 2-aminoethanol
}

\author{
Constança F.P. Silva ${ }^{\text {a }}$, Maria Leonor T.S. Duarte ${ }^{\text {a }}$, Rui Fausto ${ }^{\text {b,* }}$ \\ ${ }^{a}$ Departamento de Química e Bioquímica, Universidade de Lisboa, Campo Grande, P-1700 Lisboa, Portugal \\ ${ }^{\mathrm{b}}$ Departamento de Química, Universidade de Coimbra, P-3049 Coimbra, Portugal
}

Received 24 August 1998; received in revised form 20 October 1998; accepted 20 October 1998

\begin{abstract}
Conformational isomerism in isolated and liquid 2-aminoethanol was investigated by a concerted molecular orbital and vibrational spectroscopic approach. The molecular structures, relative energies, dipole moments and vibrational spectra (both infrared and Raman) of the various possible conformers of the studied compound were calculated, using the extended 6-31G* basis set at the HF-SCF ab initio level of theory. The theoretical results were then used to interpret infrared and Raman data obtained under different experimental conditions. It was found that none of the most populated conformational states existing in the pure liquid (where intermolecular H-bonding occurs extensively)-the gGt and tTt conformers -, correspond to the conformational ground state for the isolated 2-aminoethanol molecule - the intramolecularly H-bonded $\mathbf{g}^{\prime} \mathbf{G} \mathbf{g}^{\prime}$ conformer. (C) 1999 Elsevier Science B.V. All rights reserved.
\end{abstract}

Keywords: 2-Aminoethanol; Conformational isomerism; Infrared spectra; 6-31G* ab initio calculations; Intra and intermolecular hydrogen bonding

\section{Introduction}

2-Aminoethanol (AE) is a three-rotor molecule and is characterized by three independent torsional angles $(\mathrm{C}-\mathrm{C}-\mathrm{N}-\mathrm{lp}, \mathrm{N}-\mathrm{C}-\mathrm{C}-\mathrm{O}$ and $\mathrm{C}-\mathrm{C}-\mathrm{O}-\mathrm{H}$; lp = lone pair), giving a total of $3^{3}=27$ staggered conformations. From these conformations, 14 correspond to non-equivalent energetical forms (all staggered conformations have a mirror image except the all trans form which is unique). In this article, the notation developed by Radom et al. [1] will be used thoroughly: the conformations obtained by rotation around the central $\mathrm{C}-\mathrm{C}$ bond are indicated by a capital

\footnotetext{
* Corresponding author. Tel.: + 35139 852080; fax: + 35139 827703.

E-mail address: rfausto@gemini.ci.uc.pt (R. Fausto)
}

$\mathbf{G}\left(\mathrm{N}-\mathrm{C}-\mathrm{C}-\mathrm{O} \approx 60^{\circ}\right), \mathbf{G}^{\prime}\left(-60^{\circ}\right)$ or $\mathbf{T}\left(180^{\circ}\right)$, preceded and followed by lower-case letters which indicate the geometry adopted by the $\mathrm{C}-\mathrm{C}-\mathrm{N}-\mathrm{lp}$ and $\mathrm{C}-\mathrm{C}-\mathrm{O}-\mathrm{H}$ axes, respectively; the letters $\mathbf{g}, \mathbf{g}^{\prime}$ and $\mathbf{t}$, refer to values of the appropriate dihedral angles close to $60^{\circ},-60^{\circ}$ and $180^{\circ}$, respectively.

Conformational isomerism in $\mathrm{AE}$ has been the subject of several theoretical and experimental studies [1-19]. For the isolated molecule situation and in the gaseous phase, it has been shown that intramolecular hydrogen bonding plays a decisive role in stabilizing those conformations which correspond to the most stable conformational states of the studied molecule [1-15].

In a microwave study of 2-aminoethanol in the gaseous phase, the $\mathbf{g}^{\prime} \mathbf{G g}^{\prime}$ conformer (Fig. 1) was found to be the dominant species [2]. The stability 


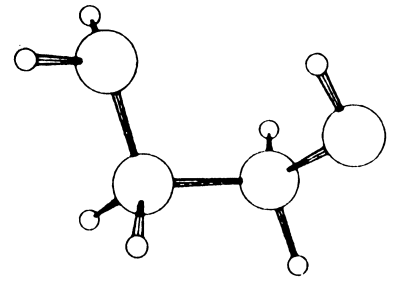

$9^{\prime} G^{\prime}$

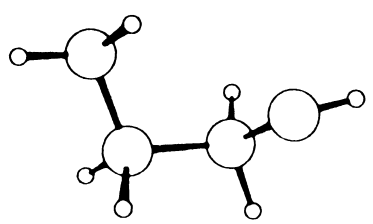

$9 G t$

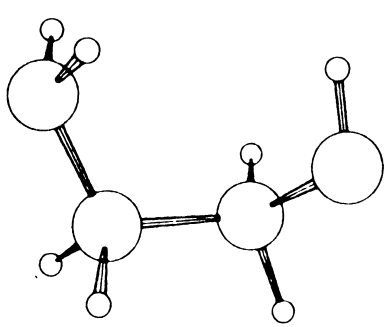

tGg

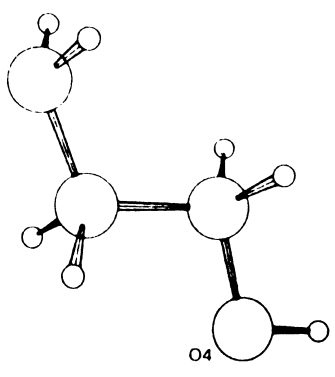

tTt

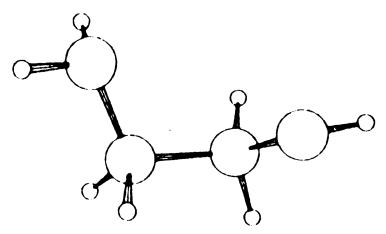

$g^{\prime} G t$

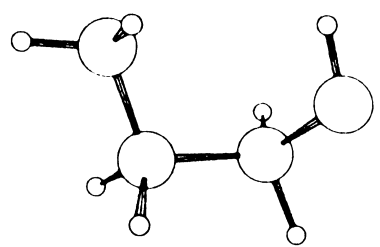

$g^{\circ}{ }^{\circ}$

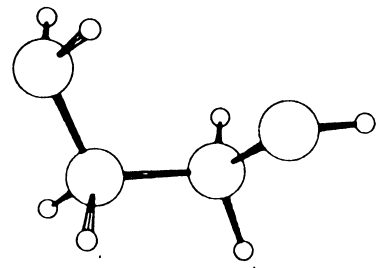

$\mathrm{tGt}$

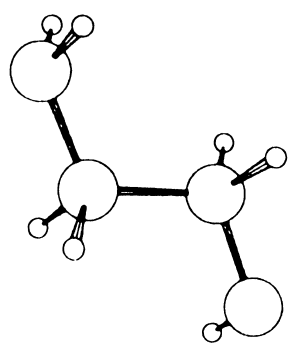

tTg

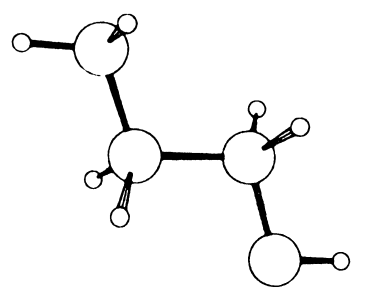

$g^{T t}$

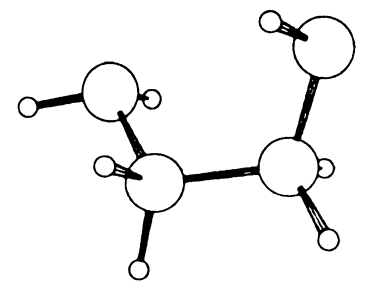

$g^{\prime} \mathrm{g}$

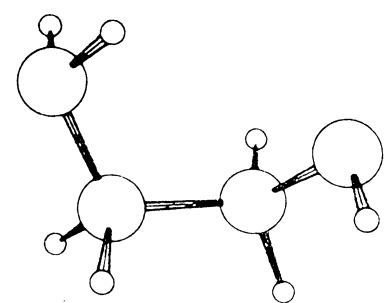

tGg

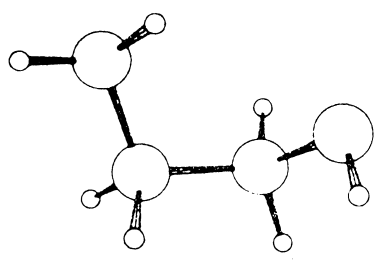

$g G_{9}$

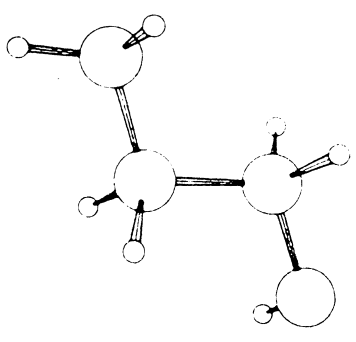

$g^{T} 9$

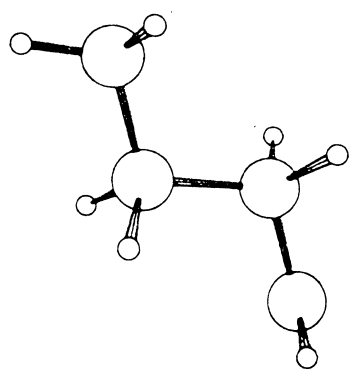

$g^{T} g$

Fig. 1. Schematic representations of the 14 non-equivalent energetically staggered conformations of 2-aminoethanol. 
of this conformer was attributed to the presence of an intramolecular hydrogen bond of the type $\mathrm{OH} \ldots \mathrm{N}$, that has also been found to operate in other similar molecules [20,21]. This result has received support from theoretical calculations carried out at different levels of approximation [3-15]. However, different methods of calculation do not fully agree with respect to the relative order of stability of the remaining conformers, despite some general consensus has emerged from the whole set of calculations already carried out: (a) conformers where $\mathrm{OH}$... $\mathrm{N}$ or $\mathrm{NH}$... O intramolecular hydrogen bonding operate have an increased stability (the estimated stabilizing energies for the stronger intramolecular $\mathrm{H}$-bonding of each type-OH...N, in $\mathbf{g}^{\prime} \mathbf{G g}^{\prime}$, and NH...O in $\mathbf{g G t}$ - amount to ca. 15 and $3 \mathrm{~kJ} \mathrm{~mol}^{-1}$, respectively [16]; (b) all forms exhibiting a Trans $\mathrm{N}-\mathrm{C}-\mathrm{C}-\mathrm{O}$ axis have energies higher than the conformational ground state by at least $10 \mathrm{~kJ} \mathrm{~mol}^{-1}$ and energy barriers for internal rotation larger than $30 \mathrm{~kJ} \mathrm{~mol}^{-1}$ [8]; (c) the real physical meaning of some of the minima observed in the predicted potential energy surfaces (PES) of $\mathrm{AE}$ $\left(\mathbf{g G g}^{\prime}, \mathbf{t G g} \mathbf{g}^{\prime}, \mathbf{g}^{\prime} \mathbf{G g}, \mathbf{g}^{\prime} \mathbf{T g}, \mathbf{g}^{\prime} \mathbf{G t}\right)$ is still questionable, as these forms are not minimum on all PES calculated or are predicted to have very low energy barriers (in some cases lower than the "conformer" zero point vibrational energy [14]).

In an infrared study of $\mathrm{AE}$ isolated in matrices at low temperature (where gas phase vibrational data was also reported) [8], the $\nu \mathrm{OH}$ and $\tau \mathrm{OH}$ spectral regions were studied in detail and the results interpreted assuming the presence in the samples of at least five different conformers: the most stable $\mathrm{OH}$... N intramolecularly H-bonded $\mathbf{g}^{\prime} \mathbf{G} \mathbf{g}^{\prime}$ form, and conformers $\mathbf{g G t}$, tGt, tGg and $\mathbf{g G g}$, all of them exhibiting an $\mathrm{NH}$... O intramolecular hydrogen bond and having relative energies to the most stable conformer within $10 \mathrm{~kJ} \mathrm{~mol}^{-1}$. Upon irradiation of the matrices in the $\nu \mathrm{OH}$ stretching region conformer $\mathbf{g}^{\prime} \mathbf{G g}^{\prime}$ converts easily to the other forms in a reversible way [8].

Despite the relatively large number of structural and conformational studies previously carried out on the isolated molecule of $\mathrm{AE}$, the vibrational data available is still very scarce and, in particular, the analyses of the vibrational spectra previously performed did not receive any systematic support from a high level theoretical model. Thus, in this study, the available spectroscopic data for AE is interpreted on the basis of predictions of vibrational spectra made by high level ab initio molecular orbital calculations.

However, AE has not been studied in detail in the liquid phase, where intermolecular interactions may change dramatically the relative importance of the various possible isomeric forms. In fact, the previously reported studies $[17,22]$ assume the existence in this phase of significant populations of both Trans and Gauche forms about the $\mathrm{N}-\mathrm{C}-\mathrm{C}-\mathrm{O}$ axis (despite the exact nature of the most abundant forms have not been identified), a result that may be considered relatively unlikely taking into consideration that these forms correspond to high energy conformational states for the isolated molecule situation. In this article, the liquid phase spectra of $\mathrm{AE}$ is analyzed in detail and the most abundant isomeric forms of this molecule present in this phase are identified.

\section{Experimental}

2-AE which was obtained commercially was the spectroscopic grade (purity 99.5+\%) and was used without any additional purification. IR spectra were obtained using a Mattson Infinity Series Fourier transform spectrometer equipped with a germanium/CsI beam splitter and a deuterated triglycine sulphide (DTGS) detector fitted with CsI windows. Data collection was performed with $2 \mathrm{~cm}^{-1}$ spectral resolution using a specially designed demountable transmission variable temperature cell with $\mathrm{AgCl}$ windows, linked to a T48 (Red Lion Controls) temperature controller.

The ab initio molecular orbital calculations were performed using the 6-31G* basis set [23] with the GAUSSIAN 92 program package [24] running on DEC ALPHA 7000 computer. Molecular geometries were fully optimized by the force gradient method using Berny's algorithm [25] and the standard convergence criteria for geometry optimization. The $6-31 \mathrm{G}^{*}$ $\mathrm{ab}$ initio calculated wavenumbers were scaled down in order to fit to the experimental values by using a single scale factor (0.89 [26]). Normal coordinate analysis were undertaken using the programs TRANSFORMER, BUILD-G and VIBRAT [27], which are interfaced with GAUSSIAN 92. 


\section{Results and discussion}

Relative energies, dipole moments and some relevant structural data of the various conformers resulting from the ab initio calculations are shown in Table 1. From these results (and in consonance with previous theoretical studies performed at similar levels of approximation [8,9,11-15]) it can be expected that the experimentally accessible conformers of isolated $\mathrm{AE}$ correspond to Gauche forms about the $\mathrm{N}-\mathrm{C}-\mathrm{C}-\mathrm{O}$ axis, the most populated species being $\mathbf{g}^{\prime} \mathbf{G} \mathbf{g}^{\prime}$ (the most stable form, which exhibits a strong intramolecular $\mathrm{OH}$... $\mathrm{N}$ hydrogen bond) the gGt and tGt conformers both stabilized by an $\mathrm{NH} . . . \mathrm{O}$ intramolecular hydrogen bond and having relative energies to the most stable form of ca. 6.0 and $7.0 \mathrm{~kJ} \mathrm{~mol}^{-1}$, respectively. Form $\mathbf{g G g}^{\prime}$ (where a weak $\mathrm{OH}$...N intramolecular $\mathrm{H}$-bond exists) is predicted by the calculations to be the $3 \mathrm{rd}$ most stable conformer, with an energy of ca. $6.5 \mathrm{~kJ} \mathrm{~mol}^{-1}$ above the most stable conformer, but, as discussed previously [14], its physical meaning is questionable, depending on the real height of the energy barrier that separates this form from the $\mathbf{g}^{\prime} \mathbf{G} \mathbf{g}^{\prime}$. Forms $\mathbf{t G g}$ and gGg have energies ca. 8.0 and $8.5 \mathrm{~kJ} \mathrm{~mol}^{-1}$ higher than the conformational ground state and correspond to the 5th and 6th more stable conformers. Assuming a Boltzmann distribution and neglecting all higher energy forms, the predicted populations of these six conformers, at room temperature, are $77.3 \%, 6.9 \%$, $5.6 \%, 4.6 \%, 3.1 \%$ and $2.5 \%$, respectively. Thus, the $\mathbf{g}^{\prime} \mathbf{G g}^{\prime}$ conformer is considerably more populated than the remaining conformers and the vibrational bands owing to this form must clearly dominate the spectra of $\mathrm{AE}$ in both the gaseous phase and in the low temperature matrices.

Table 2 summarizes the vibrational results obtained here for the most stable conformers of isolated $\mathrm{AE}$ and compares these results with the experimental gas phase and matrix isolated data $[8,28]$. As it can be noted from this Table, the theoretical results strongly support the previous conclusions from M. Räsänen et al. [8] and, in addition, enable a full assignment of the observed bands in all studied spectral regions.

The liquid phase Raman and infrared spectra of AE are shown in Fig. 2. The assignments made here are presented in Table 3. The liquid phase data are consistent with the absence of the intramolecularly $\mathrm{H}$ - bonded $\mathbf{g}^{\prime} \mathbf{G} \mathbf{g}^{\prime}$ form (and, if it exists, it also applies to the $\mathbf{g G g}^{\prime}$ conformer). In fact, the prevalent hydrogen bonding in the liquid is the intermolecular $\mathrm{OH}$... $\mathrm{N}$ bonding, whose mean energy of stabilization is known to be ca. $29 \mathrm{~kJ} \mathrm{~mol}^{-1}$ [19] (nearly twice that associated with the intramolecular process in $\mathbf{g}^{\prime} \mathbf{G} \mathbf{g}^{\prime}$ [16]). This is noticed easily by looking at the observed frequencies for the $\nu \mathrm{OH}, \delta \mathrm{COH}$ and $\tau \mathrm{OH}$ vibrations in the liquid state spectra, which are typical values for intermolecularly H-bonded hydroxyl groups [29,30]. The formation of this hydrogen bond leads necessarily to break the intramolecular $\mathrm{OH}$... $\mathrm{N}$ hydrogen bond that stabilizes the $\mathbf{g}^{\prime} \mathbf{G g}$ ' (and $\mathbf{g G g} \mathbf{g}^{\prime}$ ) conformers, making these forms unstable in the liquid. In contrast, the intermolecular $\mathrm{OH} \ldots \mathrm{N}$ hydrogen bond may, in principle, be established by all conformers having a free $\mathrm{OH}$ group and the $\mathrm{NH}_{2}$ group accessible for acting as hydrogen acceptor, including those conformers where intramolecular $\mathrm{NH}$... O hydrogen bonding is operating. Indeed, these are the best examples to be the preferred conformations of $\mathrm{AE}$ in the liquid phase, as, excluding the $\mathbf{g}^{\prime} \mathbf{G} \mathbf{g}^{\prime}$ and $\mathbf{g G g} \mathbf{g}^{\prime}$ conformers, these are the lowest energy forms in the isolated molecule situation (with gGt being the lower energy state) and

Table 1

HF 6-31G* calculated relative energies, dipole moments and $\mathrm{OH} . . . \mathrm{N}$ and $\mathrm{NH}$... O distances for the various conformational states of 2-aminoethanol ${ }^{\mathrm{a}}$

\begin{tabular}{lllll}
\hline Conformer & $\Delta E$ & $\mu$ & $r(\mathrm{OH} \ldots \mathrm{N})$ & $r(\mathrm{NH} \ldots \mathrm{O})$ \\
\hline $\mathrm{g}^{\prime} \mathrm{Gg}^{\prime}$ & 0.00 & 3.27 & $\mathbf{2 . 3 2}$ & 3.33 \\
$\mathrm{gGt}$ & 6.06 & 1.07 & 3.63 & $\mathbf{2 . 4 9}$ \\
$\mathrm{gGg}^{\prime}$ & 6.55 & 2.07 & $\mathbf{2 . 5 5}$ & 2.74 \\
$\mathrm{tGt}$ & 6.89 & 2.92 & 3.75 & $\mathbf{2 . 5 5}$ \\
$\mathrm{tGg}$ & 8.07 & 1.52 & 3.35 & $\mathbf{2 . 5 8}$ \\
$\mathrm{gGg}$ & 8.55 & 2.73 & 3.34 & $\mathbf{2 . 5 3}$ \\
$\mathrm{gTt}$ & 9.68 & 1.11 & 4.35 & 3.99 \\
$\mathrm{gTg}$ & 10.36 & 1.73 & 3.99 & 4.00 \\
$\mathrm{tTt}$ & 11.11 & 2.95 & 4.42 & 4.00 \\
$\mathrm{gTg}$ & 11.17 & 2.95 & 3.98 & 4.03 \\
$\mathrm{tTg}^{\prime}$ & 11.38 & 1.64 & 4.01 & 4.03 \\
$\mathrm{tGg}^{\prime}$ & 11.84 & 1.79 & 2.82 & 2.76 \\
$\mathrm{~g}^{\prime} \mathrm{Gt}$ & 20.07 & 2.53 & 3.75 & 3.47 \\
\hline
\end{tabular}

\footnotetext{
${ }^{\text {a }}$ Relative energies, $\Delta E$, to the most stable $\mathbf{g}^{\prime} \mathbf{G} \mathbf{g}^{\prime}$ conformer in $\mathrm{kJ}$ $\mathrm{mol}^{-1}$; dipole moments, $\mu$, in Debyes $\left(1 \mathrm{D}=3.336 \times 10^{-30} \mathrm{Cm}\right)$; distances in $\AA$. Considering the sum of van der Waals radii of hydrogen nitrogen and hydrogen + oxygen equal to 2.70 and $2.60 \AA$, respectively [8], the conformers where an intramolecular hydrogen bonding is present have their $\mathrm{OH} . . \mathrm{N}$ or $\mathrm{NH}$... O distances in bold.
} 
Table 2

Gas phase and low temperature matrix isolated spectroscopy (MIS) infrared vibrational spectra [8,28], HF 6-31G* calculated relevant infrared wavenumbers and intensities for the most populated conformational states of 2-aminoethanol and calculated potential energy distributions (PEDs) for the vibrations of the conformational ground state $\left(\mathbf{g}^{\prime} \mathbf{G} \mathbf{g}^{\prime}\right)^{\mathrm{a}}$

\begin{tabular}{|c|c|c|c|c|c|c|c|}
\hline $\begin{array}{l}\text { Gas phase } \\
\nu\end{array}$ & I & $\begin{array}{l}\mathrm{MIS}^{\mathrm{b}} \\
\boldsymbol{\nu}\end{array}$ & I & $\begin{array}{l}\text { Calculated } \\
\boldsymbol{\nu}\end{array}$ & I & $\mathrm{PED}^{\mathrm{d}}$ & Assignment $^{\mathrm{c}}$ \\
\hline 3698 & sh & 3666 & $\mathrm{~m}$ & 3668 & & & $\boldsymbol{\nu} \mathrm{OH} \mathbf{g G t}$ \\
\hline 3676 & $\mathrm{~m}$ & 3662 & $\mathrm{~m}$ & 3666 & & & $\nu \mathrm{OH} \mathbf{~ t G t}$ \\
\hline 3660 & sh & 3646 & $\mathrm{~m}$ & 3650,3651 & & & $\nu \mathrm{OH} \mathrm{tGg}, \mathbf{g G g}$ \\
\hline \multirow[t]{2}{*}{3584} & $\operatorname{sh}$ & 3573 & w & 3654 & & & $\nu \mathrm{OH} \mathbf{g G g}^{\prime}$ \\
\hline & & $3561^{\mathrm{e}}$ & sh & 3654 & & & \\
\hline \multirow[t]{3}{*}{3570} & $\mathrm{~m}$ & 3555 & $\mathrm{~m}$ & 3618 & 75.4 & $\nu \mathrm{OH}(100)$ & $\nu \mathrm{OH}$ \\
\hline & & $3548^{\mathrm{e}}$ & $\mathrm{m}$ & 3618 & & & \\
\hline & & $3534^{\mathrm{e}}$ & $\mathrm{sh}$ & 3618 & & & \\
\hline 3422 & $\mathrm{w}$ & 3416 & $\mathrm{w}$ & 3400 & 2.4 & $\nu \mathrm{NH}_{2}$ as. (98) & $\nu \mathrm{NH}_{2}$ as. \\
\hline 3356 & vw & $3350^{\mathrm{f}}$ & vw & 3323 & 1.1 & $\nu \mathrm{NH}_{2} \mathrm{~s}$ & $\nu \mathrm{NH}_{2} \mathrm{~s}$ \\
\hline \multirow[t]{2}{*}{2949} & vs & & & 2910 & 72.3 & $\begin{array}{l}\nu \mathrm{ClH}_{2} \text { as }(53)+\nu \mathrm{ClH}_{2} \mathrm{~s} .(24)+ \\
\nu \mathrm{C}_{2} \mathrm{H}_{2} \text { as. }(13)\end{array}$ & $\nu \mathrm{ClH}_{2}$ as. \\
\hline & & & & 2899 & 41.4 & $\begin{array}{l}\nu \mathrm{C} 2 \mathrm{H}_{2} \text { as. }(56)+\nu \mathrm{C} 2 \mathrm{H}_{2} \mathrm{~s} \\
(20)+\nu \mathrm{ClH}_{2} \mathrm{~s} .(12)+ \\
\nu \mathrm{ClH}_{2} \text { as. }(11)\end{array}$ & $\nu \mathrm{C} 2 \mathrm{H}_{2}$ as \\
\hline 2882 & vs & & & 2821 & 102.6 & 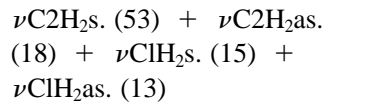 & $\nu \mathrm{C} 2 \mathrm{H}_{2} \mathrm{~s}$ \\
\hline 2861 & sh & & & 2807 & 69.2 & $\begin{array}{l}\nu \mathrm{ClH}_{2} \mathrm{~s} .(48)+\nu \mathrm{ClH}_{2} \text { as. (23) } \\
+\nu \mathrm{C} 2 \mathrm{H}_{2} \text { s. (16) }+\nu \mathrm{C}_{2} \mathrm{H}_{2} \text { as. } \\
(12)\end{array}$ & $\nu \mathrm{ClH}_{2} \mathrm{~s}$ \\
\hline 1623 & $\mathrm{~m}$ & & & 1634 & 39.2 & $\delta \mathrm{NH}_{2}(72)+\omega \mathrm{NH}_{2}(22)$ & $\delta \mathrm{NH}_{2}$ \\
\hline 1471 & w & & & 1486 & 0.3 & $\delta \mathrm{ClH}_{2}(93)$ & $\delta \mathrm{ClH}_{2}$ \\
\hline 1462 & w & & & 1469 & 2.9 & $\delta \mathrm{C} 2 \mathrm{H}_{2}(91)$ & $\delta \mathrm{C} 2 \mathrm{H}_{2}$ \\
\hline 1385 & $\mathrm{~m}$ & & & 1420 & 69.1 & $\begin{array}{l}\omega \mathrm{ClH}_{2}(44)+\delta \mathrm{COH}(16)+ \\
\omega \mathrm{C}_{2} \mathrm{H}_{2}(14)+\nu \mathrm{CC}(12)\end{array}$ & $\omega \mathrm{ClH}_{2}$ \\
\hline 1375 & sh & & & 1383 & 29.9 & $\omega \mathrm{C} 2 \mathrm{H}_{2}(58)+\omega \mathrm{ClH}_{2}(17)$ & $\omega \mathrm{C} 2 \mathrm{H}_{2}$ \\
\hline \multirow[t]{2}{*}{1359} & $\mathrm{~m}$ & & & 1342 & 13.8 & $\begin{array}{l}\delta \mathrm{COH}(33)+\mathrm{T} \omega \mathrm{ClH}_{2}(23)+ \\
\omega \mathrm{ClH}_{2}(22)\end{array}$ & $\delta \mathrm{COH}$ \\
\hline & & & & 1296 & 3.4 & $\begin{array}{l}\mathrm{T} \omega \mathrm{C} 2 \mathrm{H}_{2}(31)+\gamma \mathrm{NH}_{2}(27)+ \\
\mathrm{T} \omega \mathrm{ClH}_{2}(14)\end{array}$ & $\mathrm{T} \omega \mathrm{C} 2 \mathrm{H}_{2}$ \\
\hline 1230 & $\mathrm{~m}$ & & & 1222 & 37.3 & $\mathrm{~T} \omega \mathrm{ClH}_{2}(31)+\mathrm{T} \omega \mathrm{C} 2 \mathrm{H}_{2}(15)$ & $\mathrm{T} \omega \mathrm{ClH}_{2}$ \\
\hline 1100 & sh & & & 1153 & 11.6 & $\begin{array}{l}\gamma \mathrm{ClH}_{2}(11)+\mathrm{T} \omega \mathrm{ClH}_{2}(28)+ \\
\delta \mathrm{COH}(12)+\nu \mathrm{CO}(11)\end{array}$ & $\gamma \mathrm{ClH}_{2}$ \\
\hline 1083 & sh & & & 1035 & 19.9 & $\nu \mathrm{CN}(58)$ & $\nu \mathrm{CN}$ \\
\hline \multirow[t]{2}{*}{1037} & $\mathrm{~s}$ & & & 1093 & 86.0 & $\nu \mathrm{CO}(56)+\nu \mathrm{CC}(12)$ & $\nu \mathrm{CO}$ \\
\hline & & & & 981 & 28.7 & $\begin{array}{l}\gamma \mathrm{NH}_{2}(32)+\gamma \mathrm{ClH}_{2}(17)+ \\
\gamma \mathrm{C} 2 \mathrm{H}_{2}(17)+\omega \mathrm{NH}_{2}(14)\end{array}$ & $\gamma \mathrm{NH}_{2}$ \\
\hline 858 & $\mathrm{~m}$ & & & 841 & 25.0 & $\begin{array}{l}\nu \mathrm{CC}(44)+\nu \mathrm{CN}(22)+ \\
\gamma \mathrm{ClH}_{2}(13)\end{array}$ & $\nu \mathrm{CC}$ \\
\hline 796 & $\mathrm{~s}$ & & & 918 & 82.3 & $\omega \mathrm{NH}_{2}(49)+\tau \mathrm{NH}_{2}$ & $\omega \mathrm{NH}_{2}$ \\
\hline 759 & $\mathrm{~s}$ & & & 814 & 81.8 & $\begin{array}{l}\gamma{\mathrm{C} 2 \mathrm{H}_{2}(15)}+\omega \mathrm{NH}_{2}(15)\end{array}$ & $\gamma \mathrm{C} 2 \mathrm{H}_{2}$ \\
\hline \multirow[t]{4}{*}{540} & $\mathrm{~m}$ & 530 & $\mathrm{~m}$ & 513 & 51.7 & $\delta \mathrm{OCC}(32)+\delta \mathrm{CCN}(28)$ & $\delta \mathrm{OCC}$ \\
\hline & & 510 & w & 502 & & & $\delta \mathrm{OCC} \mathbf{g G g}{ }^{\prime}$ \\
\hline & & $459^{\mathrm{e}}$ & $\mathrm{m}$ & 469 & & & \\
\hline & & $451^{\mathrm{e}}$ & $\mathrm{m}$ & 469 & & & \\
\hline \multirow[t]{2}{*}{460} & $\mathrm{~s}$ & 447 & $\mathrm{~s}$ & 469 & 146.1 & $\tau \mathrm{OH}(78)$ & $\tau \mathrm{OH}$ \\
\hline & & $438^{\mathrm{e}}$ & w & 433 & & & \\
\hline
\end{tabular}


Table 2 (continued)

\begin{tabular}{|c|c|c|c|c|c|c|c|}
\hline $\begin{array}{l}\text { Gas phase } \\
\nu\end{array}$ & I & $\begin{array}{l}\mathrm{MIS}^{\mathrm{b}} \\
\nu\end{array}$ & I & $\begin{array}{l}\text { Calculated } \\
\nu\end{array}$ & I & $\mathrm{PED}^{\mathrm{d}}$ & Assignment $^{\mathrm{c}}$ \\
\hline & & 432 & w & 433 & & & $\tau \mathrm{OH} \mathbf{g G g}{ }^{\prime}$ \\
\hline & & $340^{\mathrm{f}}$ & $\mathrm{w}$ & 343 & & & $\delta \mathrm{OCC} \mathbf{g G t}$ \\
\hline & & 246 & w & 251 & & & $\tau \mathrm{OH} \mathbf{t G t}$ \\
\hline & & 244 & W & 245 & & & $\tau \mathrm{OH}$ gGt \\
\hline & & $320^{\mathrm{f}}$ & $\mathrm{w}$ & 310 & 1.2 & $\begin{array}{l}\delta \mathrm{CCN}(38)+\delta \mathrm{OCC}(25)+ \\
\tau \mathrm{OCCN}(19)\end{array}$ & $\delta \mathrm{CCN}$ \\
\hline & & 287 & w & 291,300 & & & $\tau \mathrm{NH}_{2} \mathbf{t G g}, \mathbf{g G g}$ \\
\hline & & 254 & $\mathrm{w}$ & 264,272 & & & $\tau \mathrm{NH}_{2}$ gGt, tGt \\
\hline & & 233 & $\mathrm{w}$ & 256 & 13.4 & $\tau \mathrm{NH}_{2}(78)+\tau \mathrm{OH}(11)$ & $\tau \mathrm{NH}_{2}$ \\
\hline & & & & 178 & 5.3 & $\tau \mathrm{OCCN}(71)+\tau \mathrm{OH}(19)$ & $\tau \mathrm{OCCN}$ \\
\hline
\end{tabular}

\footnotetext{
${ }^{\text {a }}$ Wavenumbers in $\mathrm{cm}^{-1}$; calculated wavenumbers were scaled by 0.89. Experimental intensities presented as qualitative relative intensities; calculated intensities in $\mathrm{km} \mathrm{mol}^{-1}$. Complete HF 6-31G* ab initio calculated wavenumbers and intensities (Raman and ir) and normal coordinate analysis results may be obtained from the corresponding author upon request.

${ }^{\mathrm{b}}$ Ar matrix; only the spectral regions in between $3800-3300$ and $600-200 \mathrm{~cm}^{-1}$ were studied.

${ }^{\mathrm{c}}$ Some bands are tentatively assigned to the questionable $\mathbf{g G g} \mathbf{g}^{\prime}$ conformer (see text); an alternative assignment is to attribute these bands to the $\mathbf{g}^{\prime} \mathbf{G g}^{\prime}$ conformer.

${ }^{\mathrm{d}}$ Only PED values larger than $10 \%$ are shown in this Table.

${ }^{\mathrm{e}}$ Site splitting.

${ }^{\mathrm{f}} \mathrm{N}_{2}$ or $\mathrm{Kr}$ matrix.
}

Table 3

Liquid phase infrared and Raman spectra, HF 6-31G* calculated relevant infrared wavenumbers and intensities for the most populated conformational states of 2-aminoethanol in this phase and calculated potential energy distributions (PEDs) for the vibrations of the most abundant form in the liquid $(\mathbf{g G t})^{\mathrm{a}}$

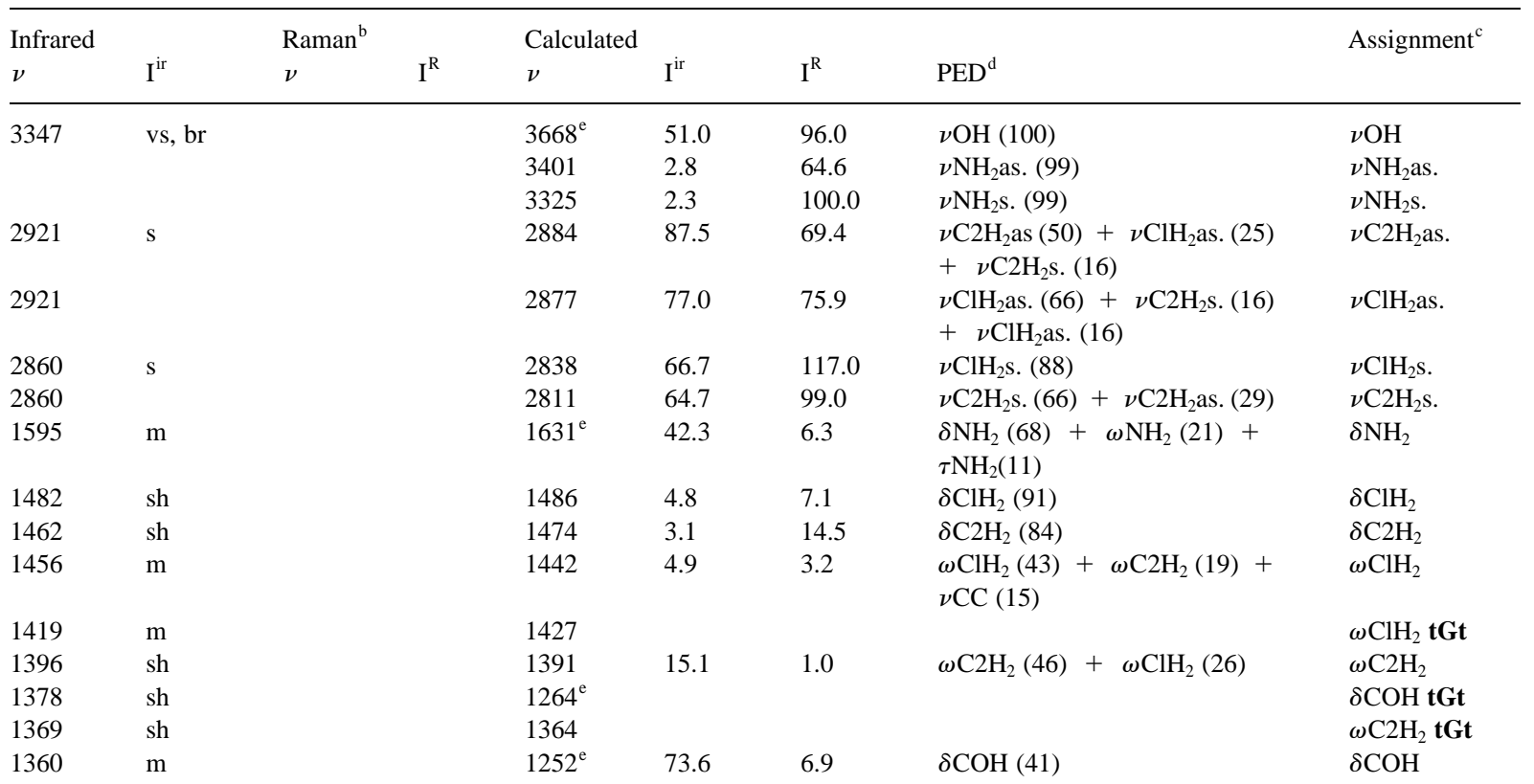


Table 3 (continued)

\begin{tabular}{|c|c|c|c|c|c|c|c|c|}
\hline $\begin{array}{l}\text { Infrared } \\
\nu\end{array}$ & $\mathrm{I}^{\mathrm{ir}}$ & $\begin{array}{l}\operatorname{Raman}^{\mathrm{b}} \\
\nu\end{array}$ & $\mathrm{I}^{\mathrm{R}}$ & $\begin{array}{l}\text { Calculated } \\
\nu\end{array}$ & $\mathrm{I}^{\mathrm{ir}}$ & $I^{R}$ & $\mathrm{PED}^{\mathrm{d}}$ & Assignment $^{\mathrm{c}}$ \\
\hline 1321 & & & & 1308 & 10.3 & 19.1 & $\begin{array}{l}\mathrm{T} \omega \mathrm{C}_{2} \mathrm{H}_{2}(42)+\gamma \mathrm{NH}_{2}(16) \\
+\mathrm{T} \omega \mathrm{ClH}_{2}(16)\end{array}$ & $\mathrm{T} \omega \mathrm{C} 2 \mathrm{H}_{2}$ \\
\hline 1242 & $\mathrm{w}$ & & & 1229 & 7.0 & 4.9 & $\begin{array}{l}\mathrm{T} \omega \mathrm{ClH}_{2}(39)+\tau \mathrm{NH}_{2}(20)+ \\
\omega \mathrm{NH}_{2}(16)\end{array}$ & $\mathrm{T} \omega \mathrm{ClH}_{2}$ \\
\hline $1165^{\mathrm{f}}$ & $\mathrm{w}$ & 1108 & $\mathrm{~m}$ & 1139 & 4.3 & 3.5 & $\begin{array}{l}\gamma \mathrm{ClH}_{2}(50) \\
\omega \mathrm{NH}_{2}(14)\end{array}+\tau \mathrm{NH}_{2}(36)+$ & $\gamma \mathrm{ClH}_{2}$ \\
\hline $1115^{\mathrm{f}}$ & w & & & & & & & \\
\hline \multirow[t]{2}{*}{1074} & $\mathrm{~s}$ & 1088 & $\mathrm{~m}$ & 1084 & 17.9 & 6.8 & $\begin{array}{l}\nu \mathrm{CO}(20)+\nu \mathrm{CN}(15)+ \\
\tau \mathrm{NH}_{2}(20)+\omega \mathrm{NH}_{2}(15)\end{array}$ & $\nu \mathrm{CO}$ \\
\hline & & 1072 & $\mathrm{sh}$ & 1081 & & & & $\nu \mathrm{CO} \mathbf{t G t}$ \\
\hline 1074 & $\mathrm{~s}$ & 1038 & w & 1069 & 82.4 & 2.3 & $\begin{array}{l}\gamma \mathrm{NH}_{2}(48)+\gamma \mathrm{ClH}_{2}(31)+ \\
\gamma{\mathrm{C} 2 \mathrm{H}_{2}(28)}\end{array}$ & $\gamma \mathrm{NH}_{2}$ \\
\hline 1028 & vs & 1000 & $\mathrm{w}$ & 1023 & 25.9 & 6.4 & $\begin{array}{l}\nu \mathrm{CN}(20)+\nu \mathrm{CO}(22)+ \\
\gamma \mathrm{NH}_{2}(16)\end{array}$ & $\nu \mathrm{CN}$ \\
\hline 1028 & vs & 984 & $\mathrm{w}$ & $880^{\mathrm{e}}$ & 152.4 & 3.2 & $\omega \mathrm{NH}_{2}(53)+\tau \mathrm{NH}_{2}(38)$ & $\omega \mathrm{NH}_{2}$ \\
\hline 874 & $\mathrm{~m}$ & 875 & $\mathrm{~m}$ & 862 & 19.6 & 5.1 & $\begin{array}{l}\nu \mathrm{CC}(44)+\nu \mathrm{CN}(22)+ \\
\gamma \mathrm{ClH}_{2}(13)\end{array}$ & $\nu \mathrm{CC}$ \\
\hline \multirow[t]{2}{*}{854} & $\mathrm{~m}$ & 848 & $\mathrm{~m}$ & 832 & 31.3 & 7.2 & $\begin{array}{l}\gamma{\mathrm{C} 2 \mathrm{H}_{2}(27)}_{\tau \mathrm{NH}_{2}(34)}+\omega \mathrm{NH}_{2}(39)+\end{array}$ & $\gamma \mathrm{C} 2 \mathrm{H}_{2}$ \\
\hline & & 834 & $\mathrm{sh}$ & 807 & & & & $\gamma \mathrm{C} 2 \mathrm{H}_{2} \mathbf{t G t}$ \\
\hline 588 & s,br & 515 & w & $245^{\mathrm{e}}$ & 160.0 & 2.5 & $\tau \mathrm{OH}(89)$ & $\tau \mathrm{OH}$ \\
\hline 477 & $\mathrm{w}$ & 484 & $\mathrm{~m}$ & 483 & 14.6 & 0.4 & $\begin{array}{l}\delta \mathrm{CCN}(41)+\delta \mathrm{COH}(21)+ \\
\omega \mathrm{NH}_{2}(14)\end{array}$ & $\delta \mathrm{CCN}$ \\
\hline $330^{\mathrm{g}}$ & w & 345 & $\mathrm{w}$ & 343 & 8.6 & 1.5 & $\begin{array}{l}\delta \text { OCC }(25)+\delta \mathrm{CCN}(37)+ \\
\tau \mathrm{OCCN}(10)\end{array}$ & $\delta \mathrm{OCC}$ \\
\hline $250^{\mathrm{g}}$ & w & 230 & w & $\begin{array}{l}264 \\
169\end{array}$ & $\begin{array}{l}58.9 \\
3.5\end{array}$ & $\begin{array}{l}1.9 \\
2.5\end{array}$ & $\begin{array}{l}\tau \mathrm{NH}_{2}(78) \\
\tau \mathrm{OCCN}(68)+\delta \mathrm{CCN}(15)\end{array}$ & $\begin{array}{l}\tau \mathrm{NH}_{2} \\
\tau \mathrm{OCCN}\end{array}$ \\
\hline
\end{tabular}

\footnotetext{
${ }^{a}$ Wavenumbers in $\mathrm{cm}^{-1}$; calculated wavenumbers were scaled by 0.89 . Experimental intensities presented as qualitative relative intensities; calculated intensities in $\mathrm{km} \mathrm{mol}^{-1}$.

${ }^{\mathrm{b}}$ Only the spectral region in between $1100-200 \mathrm{~cm}^{-1}$ was studied [17].

${ }^{\mathrm{c}}$ Bands assigned to the $\mathbf{t G t}$ conformer increase their relative intensity with temperature.

${ }^{\mathrm{d}}$ Only PED values larger than $10 \%$ are shown in this Table.

${ }^{\mathrm{e}}$ The calculated value does not fit well with the observed wavenumber as the calculations do not consider intermolecular H-bonding. As it is usually observed [29,30], when the $\mathrm{OH}$ or $\mathrm{NH}_{2}$ groups participate in $\mathrm{H}$-bonding, the wavenumbers of $\nu \mathrm{OH}, \delta \mathrm{NH}_{2}$ and $\nu \mathrm{CO}$ decrease while those of $\delta \mathrm{C}-\mathrm{O}-\mathrm{H}, \tau \mathrm{OH}$ and $\omega \mathrm{NH}_{2}$ increase.

${ }^{\mathrm{f}}$ Fermi resonance with $2 \times \tau \mathrm{OH}$.

${ }^{g}$ From Ref [17].
}

the intramolecular $\mathrm{NH} . . . \mathrm{O}$ hydrogen bonding may in fact activate both the $\mathrm{OH}$ and $\mathrm{NH}_{2}$ groups to the establishment of the $\mathrm{OH} \ldots \mathrm{N}$ intermolecular hydrogen bonding, because it makes the hydroxyl group more acidic and the amino group more basic. In addition, there are experimental evidences that conformer $\mathbf{g}^{\prime} \mathbf{G g}^{\prime}$ may be converted with relative facility to the $\mathrm{NH}$... O intramolecular hydrogen bonded conformers [8]. Accordingly, the experimental data are consistent with the $\mathbf{g G t}$ and
tGt conformers being the most abundant species in the liquid phase. Considering that, increasing the temperature leads to an increase in the relative intensity of the bands assigned to the tGt form, the conformational ground state of $\mathrm{AE}$ in the pure liquid must correspond to the $\mathbf{g G t}$ conformer (the 2nd more stable form for the isolated molecule situation). It must also be pointed out that no evidences of Trans conformers about the N-C$\mathrm{C}-\mathrm{O}$ axis were found in the liquid phase spectra. 

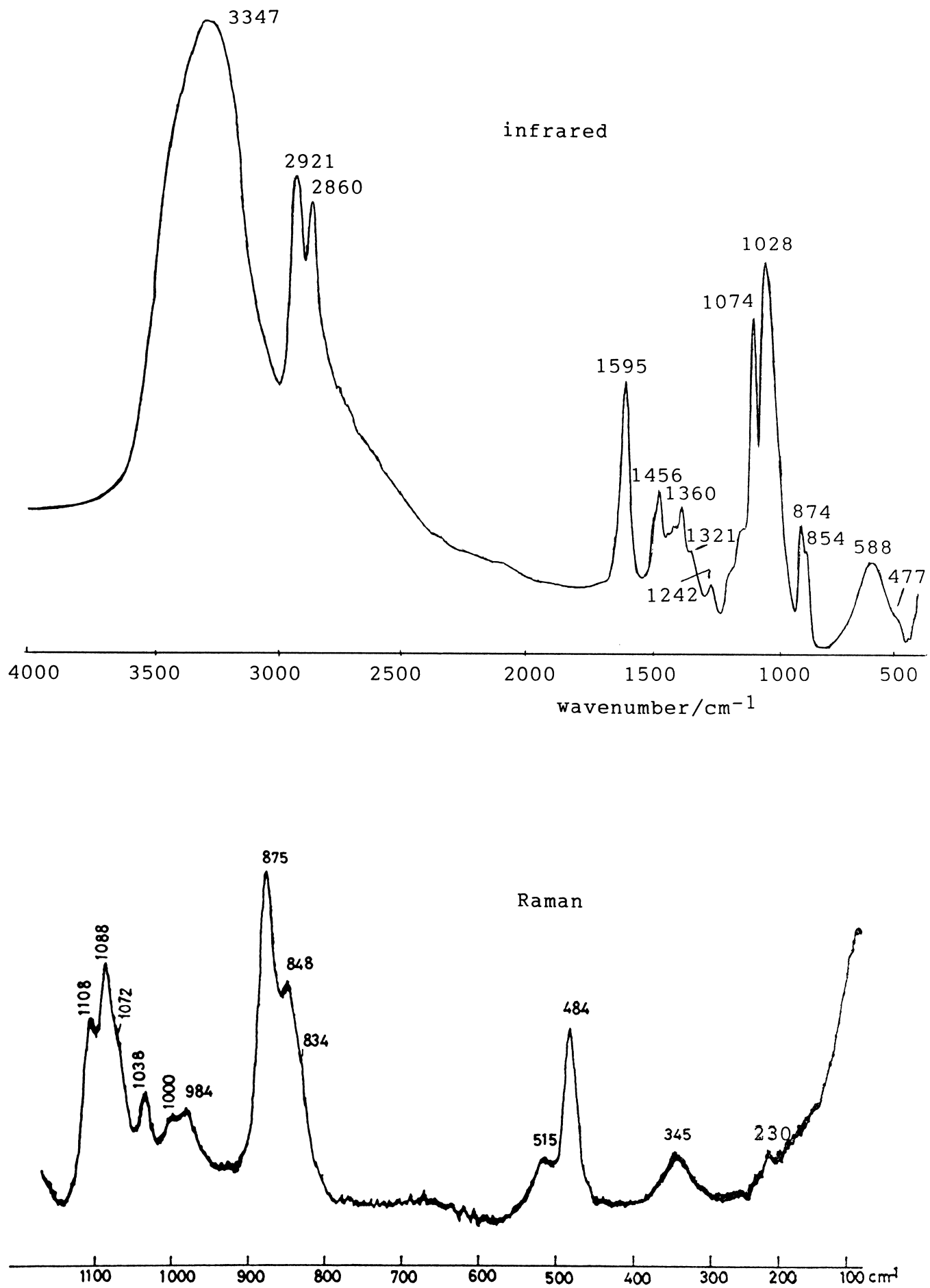

Fig. 2. Liquid phase infrared and Raman [17] spectra of 2-aminoethanol. 


\section{Acknowledgements}

This work was held within the PRAXIS XXI (QUI/ $2 / 2.1 / 412 / 94)$ research programme that is also partially funded by FEDER.

\section{References}

[1] L. Radom, W.A. Lathan, W.J. Hehre, J.A. Pople, J. Am. Chem. Soc. 95 (1973) 693.

[2] R.E. Penn, R.F. Curl Jr., J. Chem. Phys. 55 (1971) 651.

[3] R. Gunde, A. Azman, J. Mol. Struct. 27 (1975) 212.

[4] A.W. Burgess, L.L. Shipman, R.A. Nemenoff, H.A. Scheraga, J. Am. Chem. Soc. 98 (1976) 23.

[5] A. Raudino, S. Millefiori, F. Zuccarello, A. Millefiori, J. Mol. Struct. 51 (1979) 295.

[6] S. Millefiori, A. Raudino, F. Zuccarello, Z. Phys. Chem 123 (1980) 67.

[7] C. van Alsenoy, J.N. Scarsdale, J.O. Williams, L. Schäfer, J. Mol. Struct. 86 (1982) 291.

[8] M. Räsänen, A. Aspiala, L. Homanen, J. Murto, J. Mol. Struct. 96 (1982) 81

[9] C. van Alsenoy, K. Siam, J.D. Ewbank, L. Schäfer, J. Mol. Struct. (Theochem.) 136 (1986) 77.

[10] K. Ohno, K. Imai, Y. Harada, J. Am. Chem. Soc. 107 (1985) 8078.

[11] L.G. Vanquickenborne, B. Coussens, C. Verlinde, C. Ranter, J. Mol. Struct. (Theochem.) 201 (1989) 1.

[12] A.M. Kelterer, M. Ramek, J. Mol. Struct. (Theochem.) 232 (1991) 189.

[13] M. Ramek, M. Flock, A.-M. Kelterer, V.K.W. Cheng, J. Mol. Struct (Theochem.) 276 (1992) 61.

[14] A.-M. Kelterer, M. Ramek, R.F. Frey, M. Cao, L. Schäfer, J. Mol. Struct. (Theochem.) 310 (1994) 45.

[15] G. Buemi, Int. J. Quant. Chem. 59 (1996) 227.
[16] Y.-P. Chang, T.-M. Su, T.-W. Li, I. Chao, J. Phys. Chem. A101 (1997) 6107.

[17] Y. Omura, T. Shimanouchi, J. Mol. Spectrosc. 57 (1975) 480.

[18] S.T. Mulla, C.I. Jose, J. Chem. Soc. Faraday Trans. I 82 (1986) 691.

[19] P.J. Krueger, H.D. Meettee, Can. J. Chem. 43 (1965) 2970.

[20] K.-M. Marstokk, H. Mollendal, J. Mol. Struct. 35 (1967) 57.

[21] R.E. Penn, J.A. Birkenmeier, J. Mol. Spectrosc. 62 (1976) 416.

[22] M. Kuhn, W. Lüttke, R. Mecke, Z. Anal. Chem. 170 (1959) 106.

[23] W.J. Hehre, R. Ditchefield, J.A. Pople, J. Chem. Phys. 56 (1972) 2257.

[24] M.J. Frisch, G.W. Trucks, H.B. Schlegel, P.M.W. Gill, D.J. Fox, B.G. Johson, M.W. Wong, J.B. Foresman, M.A. Robb, M. Head-Gordon, E.S. Replogle, R. Gomperts, J.L. Andres, K. Raghavachari, J.S. Binkley, C. Gonzalez, R.L. Martin, D.J. Defrees, J. Baker, J.J.P. Stewart, J.A. Pople, GAUSSIAN92/ DFT (Revision G.2), Gaussian Inc., Pittsburgh PA, 1993.

[25] H.B. Schlegel, Ph.D. Thesis (Queen's University, Kingston, Ontario, Canada), 1975.

[26] J.R. Durig, Invited Oral Presentation in the NATO-ASI Conference on Low Temperature Molecular Spectroscopy, Sintra, Portugal, 1995.

[27] M.D.G. Faria, R. Fausto, TRANSFORMER, BUILD-G and VIBRAT (version 1.0), Departamento de Química, Universidade de Coimbra, Portugal, 1990.

[28] EPA Vapor Phase Library (CAS Number 141-43-5), Galactic Industries Corp., 395 Main ST. Salem, NH 03079, U.S.A., (1994).

[29] R. Fausto, J. Mol. Struct. 377 (1996) 181.

[30] E.M.S. Maçôas, Caracterização Estrutural e Espectroscópica de Ácidos Carboxílicos: Ácido Oxálico, Ácido Maleico, Ácido Fumárico e Ácido Malónico, Departamento de Química, Universidade de Coimbra, P-3049 Coimbra (Portugal), Internal Report, 1997. 